\section{Improved Plant Regeneration from Suspension-cultured Cells of Iris germanica L. 'Skating Party'}

\author{
Yuexin Wang', Zoran Jeknic ${ }^{2}$, Richard C. Ernst ${ }^{3}$, and Tony H.H. Chen ${ }^{4}$ \\ Department of Horticulture, ALS 4017, Oregon State University, Corvallis, \\ OR 97331-7304
}

Additional index words. tissue culture, embryogenesis, organogenesis, auxin, cytokinin

\begin{abstract}
To improve the efficiency of iris plant regeneration, we tested the influence of several combinations of Kin and NAA in culture media on the induction of morphogenesis and the subsequent development of plantlets. The highest rates of regeneration $(67 \%)$ were consistently observed in induction media containing $0.5 \mu \mathrm{M}$ NAA and either 2.5 or $12.5 \mu \mathrm{M}$ Kin. Developing medium containing $1.25 \mu_{\mathrm{M}}$ BA was optimal for high regeneration rates and a high percentage of plantlets simultaneously developing shoots and roots. Rooted plantlets were easily acclimatized and transplanted to various soil mixtures, then grown in the greenhouse. Under optimal conditions as many as 8000 plantlets could be regenerated from $1 \mathrm{~g}$ of cells in $\approx 4$ months. Chemical names used: kinetin(Kin); 1-naphthaleneacetic acid (NAA); N6-benzyladenine (BA).
\end{abstract}

Iris is a winter-hardy, herbaceous perennial consisting of $\approx 300$ species, many of which are popular ornamentals in the temperate regions of the Northern Hemisphere (Kohlein, 1987; Waddick and Zhao, 1992). Most horticulturally important irises are bearded species and their hybrids are derived from species native to the Near East and Europe (Kohlein, 1987). In addition to their ornamental value, Iris pallida Lam. and Iris germanica L. contain an essential oil composed partly of irones that can be extracted from rhizomes (Jéhan et al., 1994; Kohlein, 1987). These violet-scented ketonic compounds are expensive materials commonly used in cosmetics and perfumes (Gozu et al., 1993).

Iris plants are commonly propagated vegetatively using rhizomes or bulbs (Jéhan et al., 1994; Radojević and Subotić, 1992). This propagation produces a limited number of plants (two to ten plants per rhizome or bulb per year), thus requiring many years to produce commercial quantities of a new variety (Jéhan et al., 1994; Radojević and Subotić, 1992). Because of the allogamous nature of iris and the low rate of seed germination, propagation by seed is inefficient and may lead to segregation of desirable characteristics

Received for publication 26 Aug. 1998. Accepted for publication 14 Apr. 1999. Oregon Agricultural Experiment Station Technical paper no. 11391. We thank Drs. Barbara M. Reed and Bill Proebsting for their helpful reviews. The cost of publishing this paper was defrayed in part by the payment of page charges. Under postal regulations, this paper therefore must be hereby marked advertisement solely to indicate this fact.

${ }^{1}$ Graduate Research Assistant.

${ }^{2}$ Faculty Research Assistant.

${ }^{3}$ President and General Manager, Cooley's Gardens, P.O. Box 126, Silverton, OR 97381.

${ }^{4}$ Professor; to whom reprint requests should be addressed: Phone: (541) 737-5444; fax: (541) 7373479; E-mail: chent@bcc.orst.edu
(Jéhan et al., 1994). Therefore, a more efficient propagation method is needed for iris.

In addition to conventional breeding, genetic transformation offers an alternative approach to improving traits such as resistance to herbicides, diseases, and insects, or obtaining new floral colors (van Marrewijk, 1994). Genetic transformation of iris has not been reported, probably due in part to the lack of an efficient plant regeneration system.

Plants of several Iris species have been regenerated from callus culture, including $I$. germanica (Fujino et al., 1972; Gozu et al., 1993; Hussey, 1976; Jéhan et al., 1994; Laublin et al., 1991; Meyer et al., 1975; Radojević and Landré, 1990; Radojevićetal., 1987; Radojević and Subotić, 1992; Reuther, 1977; van der Linde and Hol, 1988; van der Linde et al., 1988; Yabuya et al., 1991). In addition, I. germanica has been regenerated from both protoplast (Shimizu et al., 1996) and suspension culture (Shimizu et al., 1997).

An efficient and reproducible protocol for plant regeneration from cell suspension cultures of I. germanica 'Skating Party' was developed by Wang et al. (1999). Several parameters were optimized in the cell suspension culture phase, including concentration of plant growth regulators, size of cell aggregates, and the length of subculture interval.
Table 1. Media for in vitro Iris culture and plant regeneration.

${ }^{2}$ Murashige and Skoog (1962) (M5519; Sigma, St. Louis).
The objective of this study was to further improve the efficiency of plant regeneration from suspension-cultured iris cells. We examined several factors that might affect the efficiency of plant regeneration during the induction of morphogenesis and development of plantlets, as well as during the acclimatization and establishment of plantlets in soil under greenhouse conditions.

\section{Materials and Methods}

Iris suspension cultures and media. Suspension cultures of Iris germanica 'Skating Party' established from friable calli by Wang et al. (1999) were maintained in MS-L medium (Table 1) in the dark on a gyrating shaker $(100 \mathrm{rpm})$ at $23^{\circ} \mathrm{C}$. They were subcultured every 3 weeks (unless otherwise described) by decanting MS-L medium and transferring the cells into two $250-\mathrm{mL}$ flasks, each containing $75 \mathrm{~mL}$ of MS-L medium.

Preparation of suspension cultures for plant regeneration. For regeneration experiments suspension cultures were prepared as described by Wang et al. (1999). Six-week-old cultures were screened through a 30-mesh stainless sieve. The pass-through fraction containing cell clusters $\leq 520 \mu \mathrm{m}$ in diameter was collected in 50-mL tubes and centrifuged at 1000 $g_{\mathrm{n}}$ for $10 \mathrm{~min}$ in a clinical centrifuge (HN-SII; International Equipment Co., Needham Heights, Mass.). The pelleted cells were weighed and resuspended in a liquid MS-I medium (Table 1 ) at $0.2 \mathrm{~g} \cdot \mathrm{mL}^{-1}$ final density.

Effect of Kin and NAA, alone and in combination, in MS-I medium. To induce plant morphogenesis from suspension-cultured cells, 16 different combinations of NAA $(0.0,0.5$, 2.5, and $12.5 \mu \mathrm{M})$ and $\operatorname{Kin}(0.0,2.5,12.5$, and $62.5 \mu \mathrm{M})$ were evaluated. A $0.5-\mathrm{mL}$ aliquot of the resuspended cells was inoculated on each $15 \times 60$-mm plastic plate containing $20 \mathrm{~mL}$ MS-I medium with different combinations of Kin and NAA. The cells were spread with a spoon-like spatula to form a uniform layer on the surface of MS-I medium. The plates were sealed with Parafilm ${ }^{\circledR}$ and incubated in the dark at $25^{\circ} \mathrm{C}$. The number of differentiated clumps was recorded after 5 weeks. The clumps were collected and grouped into four size classes: large $(>10 \mathrm{~mm})$, medium (5 to 10 $\mathrm{mm})$, small $(2$ to $5 \mathrm{~mm})$ and very small $(<2$ $\mathrm{mm})$.

The regeneration potential of differentiated clumps was assessed by randomly sam-

\begin{tabular}{|c|c|c|}
\hline$\overline{\text { Medium }}$ & Function & Composition \\
\hline$\overline{\mathrm{MS}-\mathrm{L}}$ & Suspension culture maintenance & $\begin{array}{l}\text { MS basal medium }{ }^{2}, 290 \mathrm{mg} \cdot \mathrm{L}^{-1} \text { proline, } 50 \mathrm{~g} \cdot \mathrm{L}^{-1} \\
\quad \text { sucrose, } 5.0 \mu_{\mathrm{M}} 2,4-\mathrm{D} \text {, and } 0.5 \mu_{\mathrm{M}} \mathrm{Kin}, \mathrm{pH} \text { 5.9. }\end{array}$ \\
\hline MS-I & Shoot induction & $\begin{array}{l}\text { MS basal medium, } 250 \mathrm{mg} \cdot \mathrm{L}^{-1} \text { proline, } 250 \mathrm{mg} \cdot \mathrm{L}^{-1} \\
\text { casein hydrolysate, } 10 \mathrm{mg} \cdot \mathrm{L}^{-1} \text { pantothenic acid, } \\
4.5 \mathrm{mg} \cdot \mathrm{L}^{-1} \text { niacin, } 1.9 \mathrm{mg} \cdot \mathrm{L}^{-1} \text { thiamin, } 50 \mathrm{~g} \cdot \mathrm{L}^{-1} \\
\text { sucrose, } 2.0 \mathrm{~g} \cdot \mathrm{L}^{-1} \text { Phytagel (Sigma), Kin }{ }^{y} \text { and } \\
\text { NAA }^{y}(\mathrm{pH} 5.7)\end{array}$ \\
\hline MS-D & Shoot elongation and development & $\begin{array}{l}\text { MS-I medium without Kin and NAA but } \\
\text { supplemented with } \mathrm{BA}^{\mathrm{y}} \text {. }\end{array}$ \\
\hline MS-R & Rooting and development of plantlets & MS-I medium without plant growth regulators. \\
\hline
\end{tabular}

y The concentrations of Kin, NAA, and BA used are given in the text. 
pling 30 to 60 clumps from each size class and transferring them to three to six Magenta GA7 vessels (Sigma Chemical Co., St. Louis) containing $50 \mathrm{~mL}$ of MS-D medium (Table 1) supplemented with $1.25 \mu \mathrm{M}$ BA. They were then incubated under light with a 16-h photoperiod of $50 \mu \mathrm{mol} \cdot \mathrm{m}^{-2} \cdot \mathrm{s}^{-1}$, provided by coolwhite fluorescent lamps, at $23^{\circ} \mathrm{C}$ for 6 weeks. The total number of regenerating clumps (i.e., differentiated clumps that continued to grow and develop on MS-D medium) was counted, and percentages of regenerating clumps that developed shoots only or plantlets (rooted shoots derived from somatic embryos) were recorded. The regenerated shoots and plantlets were transferred to MS-R medium (Table 1) to promote root development. Each Kin/ NAA combination was evaluated in five plates per experiment; the entire experiment was repeated three times.

Effect of BA concentration in MS-D medium. Several concentrations of BA in MS-D media were evaluated for their effects on further growth and development of randomly sampled differentiated clumps from the MS-I medium containing $2.5 \mu \mathrm{M}$ Kin and $0.5 \mu \mathrm{M}$ NAA. At the developing stage, 15 to 21 differentiated clumps were transferred to three to six Magenta GA-7 vessels containing $50 \mathrm{~mL}$ MSD medium supplemented with $0.0,1.25$, or 2.5 $\mu \mathrm{M}$ BA. The clumps were incubated under light with a 16 -h photoperiod of $50 \mu \mathrm{mol} \cdot \mathrm{m}^{-2} \cdot \mathrm{s}^{-1}$ at $23{ }^{\circ} \mathrm{C}$ for 6 weeks. The experiment was repeated three times.

The numbers of regenerating clumps that developed shoots only or plantlets were recorded and expressed as percentages of the total number of regenerating clumps. The effect of BA concentration on growth and development of shoots and plantlets was assessed by measuring the length of the shoots.

Relationship between size and age of differentiated clumps and their regeneration potential. To determine the optimal period to maintain clumps, we inoculated the screened cells onto MS-I medium containing $2.5 \mu \mathrm{M}$ Kin and $0.5 \mu \mathrm{M}$ NAA, then incubated them in the dark at $25^{\circ} \mathrm{C}$ for 5 weeks. The differentiated clumps were collected and grouped into the four size classes described earlier. The number of clumps in each class was recorded and the clumps were placed back onto the same MS-I medium. They were continuously cultured under the same conditions for another 4 weeks. Changes in size and distribution of differentiated clumps in each size class were recorded weekly. Every week 45 clumps from each class were transferred to Magenta GA-7 vessels (15 clumps per vessel) containing 50 $\mathrm{mL}$ MS-D medium with $1.25 \mu \mathrm{M}$ BA, then incubated under light with a $16-\mathrm{h}$ photoperiod of $50 \mu \mathrm{mol} \cdot \mathrm{m}^{-2} \cdot \mathrm{s}^{-1}$ at $23^{\circ} \mathrm{C}$. After 6 weeks, the regeneration potential $(\%)$ and the percentage of clumps that developed large shoots $(>3 \mathrm{~cm}$ long) were recorded for each size class.

Effects of potting substrates and acclimatization conditions on survival and growth of plantlets in the greenhouse. Rooted plantlets were cultured for 6 weeks on MS-R media, then transferred to $1.5-\mathrm{L}$ pots in the greenhouse. The eight substrates tested were: peatmoss; perlite; sandy loam; 1 peatmoss : 1 sandy loam $(\mathrm{v} / \mathrm{v}) ; 1$ peatmoss : 1 perlite $(\mathrm{v} / \mathrm{v})$; 1 perlite : 1 sandy loam (v/v); 1 peatmoss : 1 perlite : 1 sandy loam (by volume); and 1 peatmoss : 1 pumice : 1 sandy loam (by volume). Forty plantlets (eight pots $\times$ five plantlets per pot) were tested in each substrate with 20 plantlets per group. One group was maintained on a mist bench, with relative humidity $(\mathrm{RH}) \approx 98 \%$ (misting at 1-min intervals). The other group was placed on a non-misted bench with $\mathrm{RH} \approx 60 \%$ to $80 \%$, and was watered every other day. The experiment was repeated twice. All plants were fertilized with a controlledrelease fertilizer [Nutricot-Type $100(16 \mathrm{~N}-$ 4.4P-8.3K); Chisso-Asahi ${ }^{\circledR}$, FertilizerCo.Ltd., Tokyo). The greenhouse was maintained at 16-h days/8-h nights of $25 \pm 3{ }^{\circ} \mathrm{C} / 20 \pm 3{ }^{\circ} \mathrm{C}$ with a 16-h photoperiod. Light supplement was provided by high-pressure sodium lamps (Energy Technics, York, Pa.) to give photosynthetically active radiation of $\approx 400$ to 500 $\mu \mathrm{mol} \cdot \mathrm{m}^{-2} \cdot \mathrm{s}^{-1}$.

After 6 weeks plants from the mist bench were transferred to the nonmisted bench, and survival was recorded 6 weeks later. The effects of different substrates and acclimatization conditions on plant growth and development were assessed by measuring the fresh weights of plants after 4 months.

The data from all experiments were subjected to analysis of variance (ANOVA) and regression procedures (SAS Institute, 1987).

\section{Results}

Effects of Kin and NAA, alone and in combination, in MS-Imedium. Some white, globu- lar embryo-like structures differentiated from suspension-cultured cells after 2 weeks on MS-I media. By Week 6, all 16 combinations of Kin and NAA had given rise to such structures, but the number of differentiated clumps differed significantly among growth regulator treatments (Fig. 1). ANOVA revealed that the main effects of Kin and NAA were significant $(P \leq 0.0001)$, as well as the interaction effect $(P \leq 0.04)$. The largest numbers of differentiated clumps were obtained from the MS-I medium with $2.5 \mu \mathrm{M}$ Kin and no NAA and from the MS-I medium without growth regulators. Generally, the lower concentrations of Kin and NAA induced the largest number of differentiated clumps per gram of suspensioncultured cells.

Six weeks after differentiated clumps were transferred to MS-D medium containing 1.25 $\mu \mathrm{M}$ BA, the clumps from MS-I media with 0.5 $\mu \mathrm{M}$ NAA and either 2.5 or $12.5 \mu \mathrm{M}$ Kin showed the highest regeneration potential (67\%; Table 2 ). The main effect of NAA, but not of Kin, on regeneration was significant $(P \leq 0.001)$. However, most regenerating clumps developed plantlets $(84 \%$ to $100 \%)$ irrespective of the NAA/Kin combinations.

The most desirable clumps (those larger than $10 \mathrm{~mm}$ ) also were derived from the combination of $0.5 \mu \mathrm{M}$ NAA and either 2.5 or 12.5 $\mu_{\mathrm{M}}$ Kin (data not shown). Clumps representing the size classes are shown in Fig. 2A.

Effect of BA concentration in $M S-D$ medium. The concentration of BA did not have a significant effect on regeneration rate $(\%)$ but substantially influenced the development of large shoots from differentiated clumps (Table $3)$. The highest percentage of regenerating

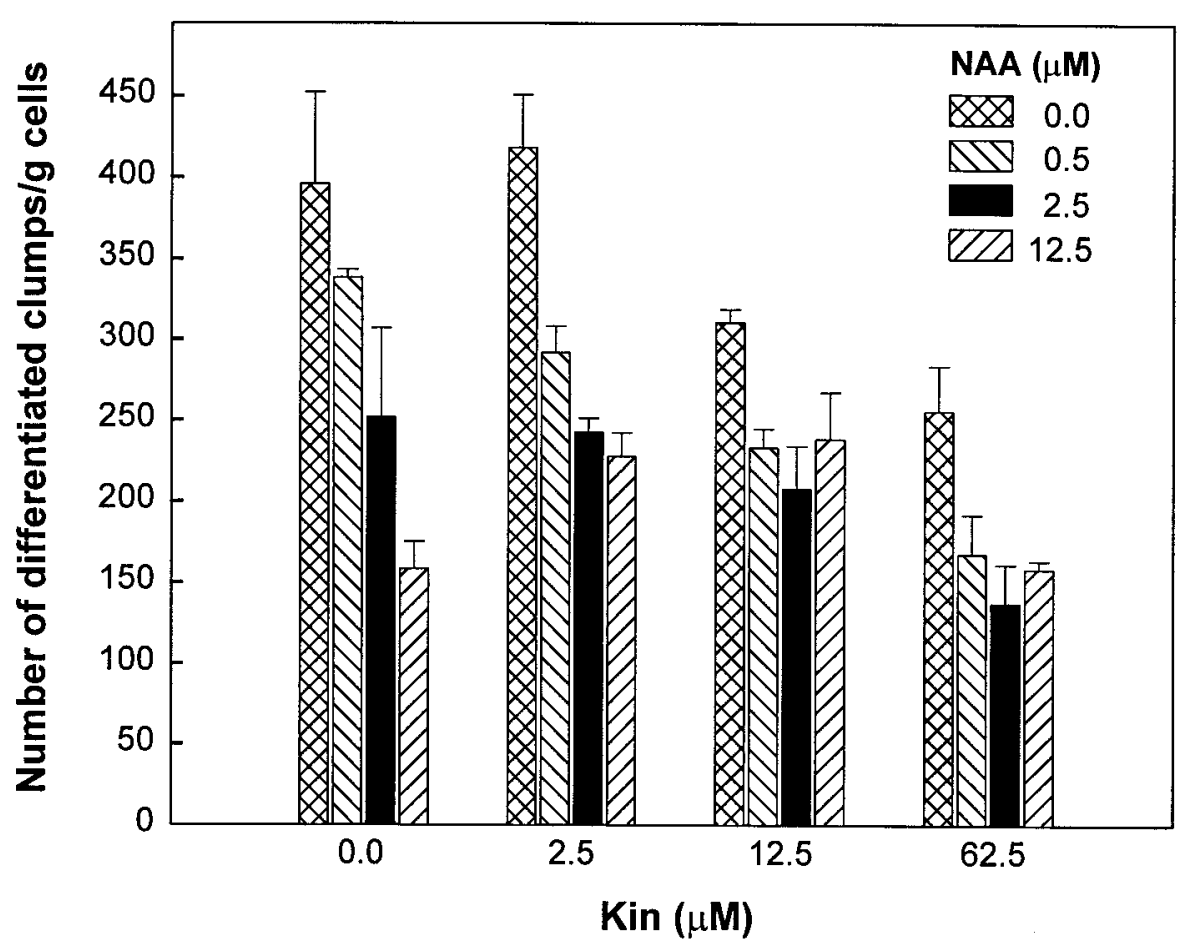

Fig. 1. Effects of Kin and NAA, alone and in combination, on the number of differentiated clumps from suspension-cultured cells of Iris germanica after 6 weeks on MS-I media. Vertical bars are standard errors. 

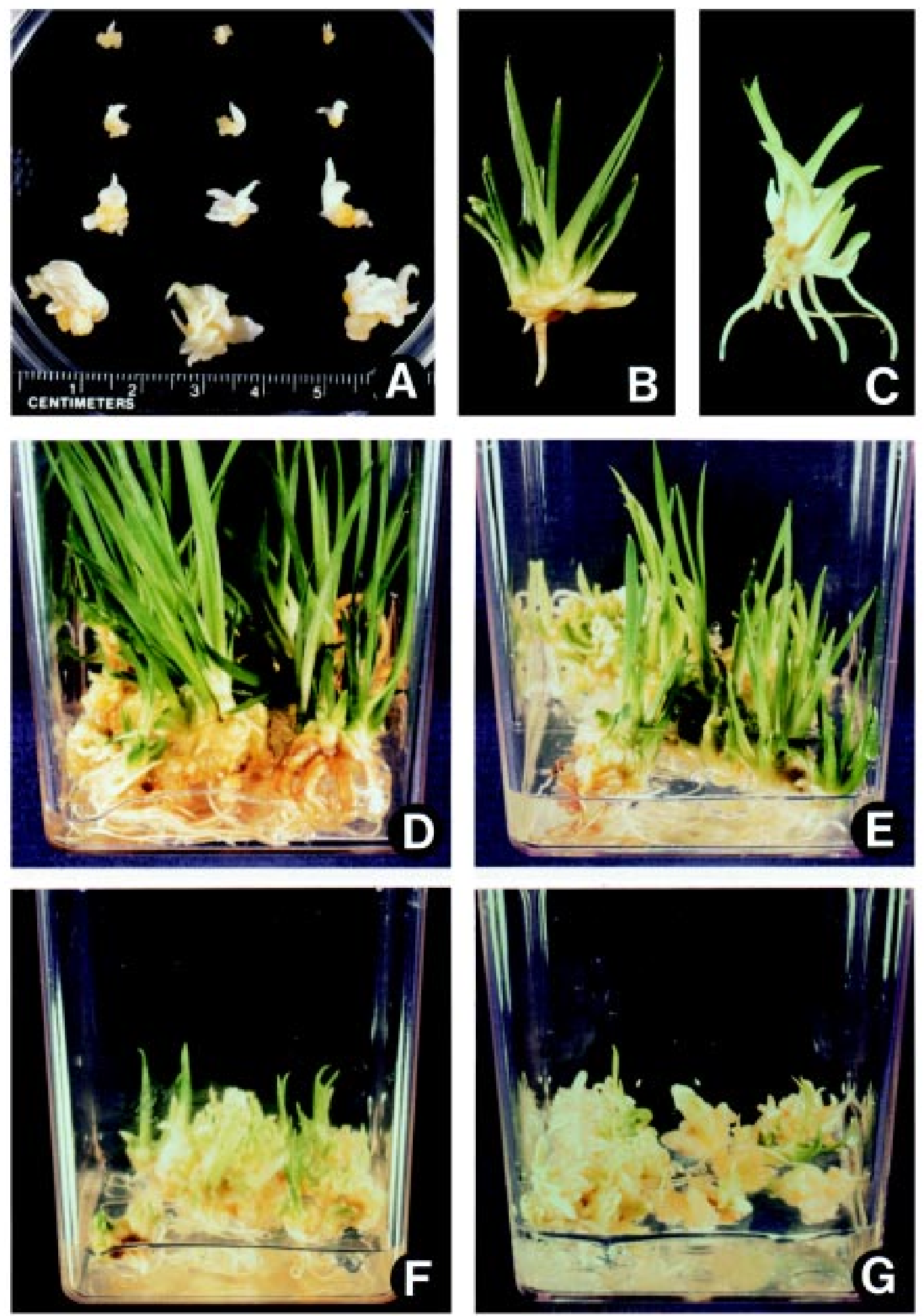

Fig. 2. (A) Classification of differentiated clumps according to size 5 weeks after inoculation of suspension-cultured iris cells on an MS-I medium. Size classes from bottom to top are large $(>10 \mathrm{~mm})$, medium $(5$ to $10 \mathrm{~mm})$, small $(2$ to $5 \mathrm{~mm})$, very small $(<2 \mathrm{~mm})$. (B) MS-D medium with $2.5 \mu \mathrm{M}$ BA enhanced shoot development but the majority of shoots developed small roots or no roots at all. (C) Simultaneous development of shoots and roots, i.e., plantlets on MS-D medium containing $1.25 \mu \mathrm{M}$ BA. (D-G) Effects of clump size on regeneration potential and development of shoots and roots after 6 weeks on MS-D medium containing $1.25 \mu \mathrm{M} \mathrm{BA}$. Regeneration potential, the tendency to simultaneously develop shoots and roots, i.e., plantlets, and the ability to produce large shoots (>3 cm long) decreased with size of clump. (D) Large; (E) medium; (F) small; and (G) very small. 
Table 2. Effects of Kin and NAA, alone and in combination in MS-I medium, on subsequent regeneration potential of differentiated clumps of Iris tissue and development of shoots or plantlets (rooted shoots) after 6 weeks on MS-D medium with $1.25 \mu \mathrm{M}$ BA.

\begin{tabular}{|c|c|c|c|c|c|}
\hline \multirow{2}{*}{\multicolumn{2}{|c|}{$\begin{array}{c}\text { Growth regulator } \\
\qquad(\mu \mathrm{M})\end{array}$}} & \multirow{2}{*}{$\begin{array}{l}\text { Mean no. } \\
\text { clumps } \\
\text { tested }\end{array}$} & \multirow{2}{*}{$\begin{array}{c}\text { Regenerating } \\
\text { clumps }^{\mathrm{z}} \\
(\%)\end{array}$} & \multicolumn{2}{|c|}{$\begin{array}{l}\text { Regenerating clumps } \\
\text { developing }(\%) \text { : }\end{array}$} \\
\hline & & & & Shoots only & Plantlets \\
\hline \multirow[t]{4}{*}{ NAA } & 0.0 & 41 & 23 & 12 & 89 \\
\hline & 0.5 & 43 & 56 & 6 & 94 \\
\hline & 2.5 & 36 & 55 & 11 & 89 \\
\hline & 12.5 & 38 & 33 & 7 & 94 \\
\hline \multirow[t]{4}{*}{ Kin } & 0.0 & 43 & 37 & 7 & 93 \\
\hline & 2.5 & 45 & 41 & 5 & 96 \\
\hline & 12.5 & 36 & 44 & 12 & 89 \\
\hline & 62.5 & 36 & 45 & 12 & 88 \\
\hline \multicolumn{6}{|c|}{ Significance } \\
\hline \multicolumn{2}{|c|}{ Kin } & & NS & NS & NS \\
\hline \multicolumn{2}{|c|}{ NAA } & & $* * *$ & NS & NS \\
\hline \multicolumn{2}{|c|}{ Kin $\times$ NAA } & & NS & NS & NS \\
\hline
\end{tabular}

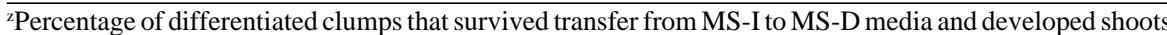
only or plantlets.

Ns, ***N Nonsignificant or significant at $P \leq 0.001$, respectively.

Table 3. Effect of BA concentration on development of shoots or plantlets (rooted shoots) from differentiated clumps $^{\mathrm{z}}$ of Iris suspension cultures on MS-D medium.

\begin{tabular}{lccccc}
\hline \hline BA & No. clumps & $\begin{array}{c}\text { Regenerating } \\
\text { clumps }^{\mathrm{y}}\end{array}$ & \multicolumn{2}{c}{ Regenerating clumps developing $(\%):$} \\
\cline { 3 - 6 }$(\mu \mathrm{M})$ & tested & $54)$ & Shoots only & Plantlets & Large shoots $^{\mathrm{x}}$ \\
\hline 0.0 & 63 & 67 & 12 & 88 & 23 \\
1.25 & 63 & 69 & 3 & 97 & 82 \\
2.5 & 45 & $0.19^{\mathrm{Ns}}$ & $0.08^{\mathrm{Ns}}$ & 55 & 72 \\
$R^{2}$ & & & $0.43^{\mathrm{Ns}}$ & $0.59^{*}$ \\
\hline
\end{tabular}

${ }^{\mathrm{z}}$ The differentiated clumps were produced on MS-I medium containing $2.5 \mu \mathrm{M}$ Kin and $0.5 \mu \mathrm{M}$ NAA.

${ }^{y}$ Percentage of differentiated clumps that survived transfer from MS-I to MS-D media and developed shoots only or plantlets.

${ }^{x}$ Shoots $>3 \mathrm{~cm}$ long.

Ns, *Nonsignificant or significant at $P \leq 0.05$.

clumps (69\%), i.e., differentiated clumps that survived transfer from MS-I to MS-D media and eventually developed shoots and plantlets, was obtained from MS-D medium containing $2.5 \mu \mathrm{M}$ BA. However, only $55 \%$ of the differentiated clumps simultaneously developed both shoots and roots (plantlets) on this medium. The majority of shoots from the MSD medium containing $2.5 \mu \mathrm{MBA}$ showed poor rooting or developed no roots at all after transfer to MS-R medium. Apparently, this concentration of BA enhanced shoot development but inhibited rooting (Fig. 2B).

The MS-D medium containing $1.25 \mu \mathrm{MBA}$ gave a slightly lower regeneration rate $(67 \%)$ but strongly stimulated simultaneous development of shoots and roots (97\%; Fig. 2C). Subsequently, shoots from the MS-D medium with 0 or $1.25 \mu \mathrm{M}$ BA readily developed roots on the MS-R medium. In addition, the highest proportion of clumps $(82 \%)$ that developed large shoots ( $>3 \mathrm{~cm}$ long) was obtained from the MS-D medium with $1.25 \mu \mathrm{M}$ BA. Generally, the number of regenerated shoots ranged from 15 to 20 shoots/clump (data not shown).

Relationship between size and age of differentiated clumps and their regeneration potential. The changes in the distribution of clumps among the four size classes during prolonged incubation on MS-I media (with 2.5 $\mu \mathrm{M}$ Kin and $0.5 \mu_{\mathrm{M}}$ NAA) were monitored from Week 6 to Week 9. The proportion of large clumps (>10 mm) increased from $29 \%$ to $86 \%$ (Fig. 3). After 6 weeks on MS-I media, the regeneration potentials of the large, me- dium, small, and very small clumps were $100 \%, 95 \%, 91 \%$, and $82 \%$, respectively (Table 4). During prolonged incubation on MS-I medium, regeneration of the large clumps remained high, while that of the medium, small and very small size clumps decreased sharply. Only $54 \%, 35 \%$, and $0 \%$ of the medium, small and very small clumps, respectively, developed shoots after 9 weeks of incubation. The ability to develop large shoots ( $>3 \mathrm{~cm}$ long) declined during prolonged incubation on MSI medium, regardless of size (Table 4). The highest overall regeneration per gram of suspension-cultured cells was always obtained from 6-week-old clumps.

We also characterized the quality of regenerating clumps by the size of shoots developing from different sized clumps after 6 weeks on MS-D medium containing $1.25 \mu \mathrm{M}$ BA (Fig. 2D-G). The ability to develop large shoots (>3 cm long) declined with size of the clumps, as did the tendency to simultaneously develop both shoots and roots (Fig. 2D-G).

Effects of substrate type and acclimatization condition on plant establishment in the greenhouse. Plant survival and growth after transfer from in vitro culture to potting substrates under greenhouse conditions varied among the eight different substrates $(P \leq 0.05$; Table 5). The substrates composed of peatmoss, perlite, and sandy loam or peatmoss, pumice, and sandy loam promoted the highest plant recovery and plant growth. The effect of misting on plant survival was not significant $(P>$ $0.35)$.

\section{Discussion}

The specific combination of auxin and cytokinin in culture media is one of the most important factors for in vitro plant regeneration of Iris (Gozu et al., 1993; Jéhan et al., 1994; Laublin et al., 1991; Radojević et al., 1987; Radojević and Subotić, 1992; Shimizu et al., 1996). Generally, 2,4-D (2,4-dichlorophenoxyacetic acid) is the most effective auxin for inducing embryogenic calli. Such results were found in regeneration of rice (Oryza sativa L.) plants from cell suspension cultures (Inoue and Maeda, 1980; Ling et al., 1983; Ozawa and Komamine, 1989; Tsukahara and Hirosawa, 1992; Tsukahara et al., 1996). Carrot (Daucus carota L.) suspension cultures transferred from media containing high concentrations of 2,4-D to media containing low concentrations readily regenerated somatic embryos (Fujimura and Komamine, 1980; Smith and Street, 1974). However, 2,4-D in liquid medium is essential for suspension cultures to grow continuously, and stimulates formation of proembryogenic or proorganogenic masses. Proembryogenic masses were critical for subsequent regeneration of carrot plants on low or no 2,4-D media (Halperin, 1966).

Kin has been used extensively in the induction and maintenance of embryogenic callus in Iris (Gozu et al., 1993; Jéhan et al., 1994; Radojević and Subotić, 1992; Shimizu et al., 1996, 1997). Somatic embryogenesis and/or shoot organogenesis are induced when embryogenic calli are transferred to media containing low or no Kin. In the current study, the lower concentration of Kin was most desirable for inducing plant morphogenesis (somatic embryogenesis and shoot organogenesis) from iris suspension-cultured cells. Our results are consistent with those of previous reports.

Kawase et al. (1995) concluded that shoot regeneration from perianth-ovary junctions and ovaries of Japanese iris (Iris ensata Thunb.) was strongly affected by BA and NAA in the medium. They found that high concentrations of both BA and NAA inhibited rooting of the upper portions of ovary explants. We observed that the BA concentration did not have a significant effect on percentage regeneration but substantially influenced the development of shoots and plantlets from differentiated clumps. For example, while the MS-D medium with $2.5 \mu \mathrm{M}$ BA enhanced shoot development, only $55 \%$ of regenerating clumps from this medium simultaneously developed shoots and roots (plantlets) (Table 3 ). Furthermore, $2.5 \mu \mathrm{M}$ BA in the MS-D medium inhibited subsequent rooting on MS-R medium (Fig. 2B). Although a concentration of 1.25 $\mu \mathrm{M}$ gave somewhat lower regeneration rates $(67 \%)$ it strongly promoted development of plantlets (97\%; Table 3, Fig. 2B). Shoots from this medium readily rooted after transfer to an MS-R medium.

Based on Wang et al. (1999) and the current study, the optimal conditions for efficient in vitro plant regeneration from suspensioncultured cells of Iris are 1) suspension-cultured cells should be grown in MS-L medium 


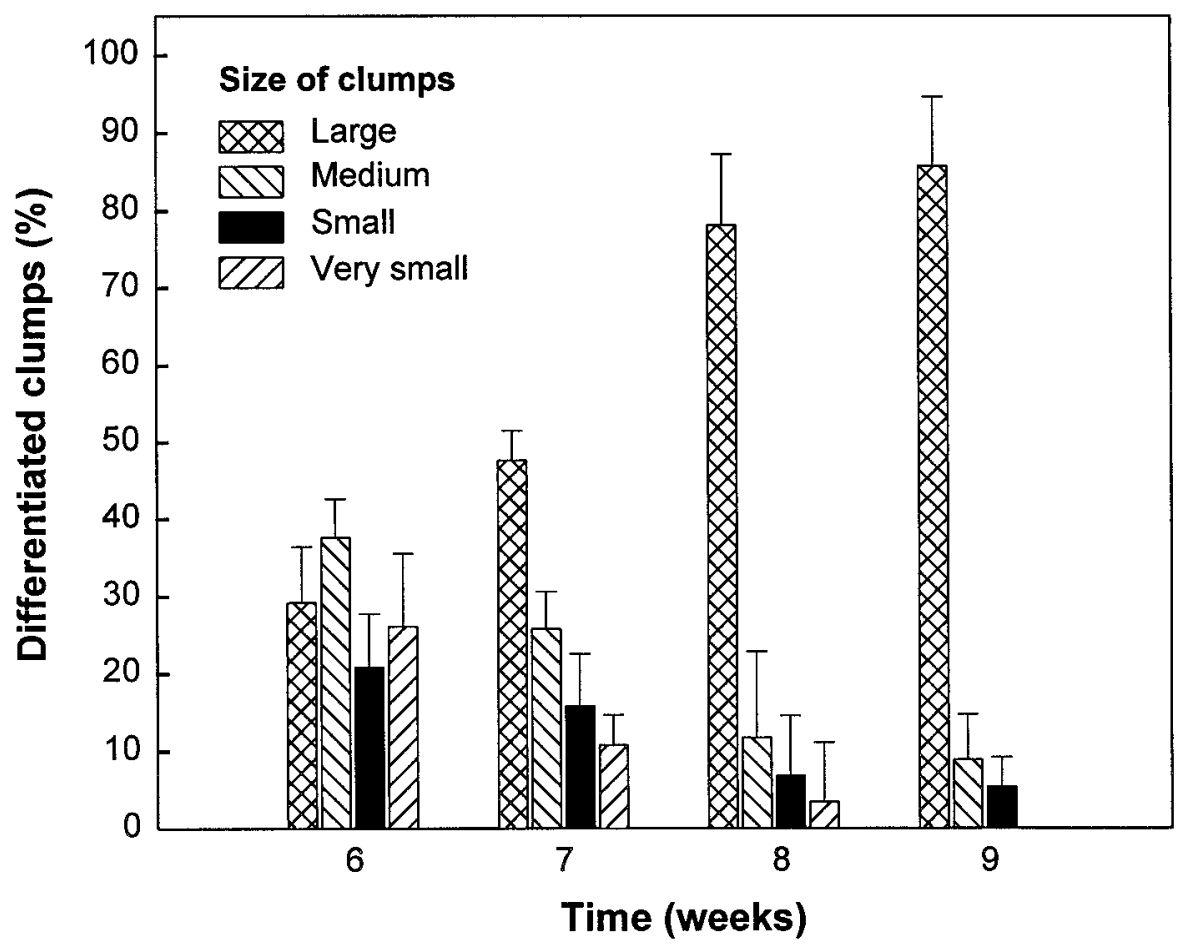

Fig. 3. Changes in distribution of clumps among four size classes during prolonged incubation ( 6 to 9 weeks) on MS-I medium containing $2.5 \mu \mathrm{M}$ Kin and $0.5 \mu \mathrm{M}$ NAA. Vertical bars are standard errors. Size classes are large $(>10 \mathrm{~mm})$, medium $(5$ to $10 \mathrm{~mm})$, small $(2$ to $5 \mathrm{~mm})$, very small $(<2 \mathrm{~mm})$.

Table 4. Effects of age and size ${ }^{z}$ of differentiated clumps of Iris suspension culture on regeneration potentials and development of large shoots. ${ }^{y}$

\begin{tabular}{|c|c|c|c|c|c|c|c|c|}
\hline \multirow{2}{*}{$\begin{array}{l}\text { Age of } \\
\text { clumps } \\
\text { (weeks) }\end{array}$} & \multicolumn{4}{|c|}{ Regeneration $(\%)$} & \multicolumn{4}{|c|}{ Clumps developing large shoots $(\%)$} \\
\hline & Large & Medium & Small & Very small & Large & Medium & Small & Very small \\
\hline 6 & 100 & 95 & 91 & 82 & 91 & 77 & 45 & 33 \\
\hline 7 & 100 & 93 & 85 & 63 & 91 & 66 & 38 & 17 \\
\hline 8 & 100 & 73 & 56 & 39 & 78 & 55 & 26 & 10 \\
\hline 9 & 98 & 54 & 35 & 0 & 74 & 37 & 23 & 0 \\
\hline \multicolumn{9}{|l|}{ Significance } \\
\hline Age & \multicolumn{4}{|c|}{$* * *$} & \multicolumn{4}{|c|}{$* * * *$} \\
\hline Size & \multicolumn{4}{|c|}{$* * *$} & \multicolumn{4}{|c|}{$* * *$} \\
\hline Age $\times$ size & \multicolumn{4}{|c|}{ *** } & \multicolumn{4}{|c|}{ NS } \\
\hline
\end{tabular}

${ }^{\mathrm{z}}$ Size classes: Large (>10 mm), medium (5 to $\left.10 \mathrm{~mm}\right)$, small $(2$ to $5 \mathrm{~mm})$, very small $(<2 \mathrm{~mm})$.

${ }^{\mathrm{y}}$ Shoots $>3 \mathrm{~cm}$ long

ss, ${ }^{* * *}$ Nonsignificant or significant at $P \leq 0.001$, respectively.

Table 5. Effects of different potting substrates on plant survival and growth (fresh weight) of Iris plantlets after 6 months of cultivation in the greenhouse.

\begin{tabular}{lcc}
\hline \hline Substrate & Survival (\%) & Fresh wt (g) \\
\hline Peatmoss & $50 \mathrm{~b}^{2}$ & $29 \mathrm{~cd}$ \\
Perlite & $58 \mathrm{~b}$ & $16 \mathrm{~d}$ \\
Sandy loam & $85 \mathrm{a}$ & $48 \mathrm{bc}$ \\
Peatmoss : sandy loam & $70 \mathrm{ab}$ & $55 \mathrm{ab}$ \\
Peatmoss : perlite & $85 \mathrm{a}$ & $33 \mathrm{~cd}$ \\
Perlite : sandy loam & $88 \mathrm{a}$ & $45 \mathrm{bc}$ \\
Peatmoss : perlite : sandy loam & $83 \mathrm{a}$ & $71 \mathrm{a}$ \\
Peatmoss : pumice : sandy loam & $90 \mathrm{a}$ & $68 \mathrm{a}$
\end{tabular}

${ }^{2}$ Mean separation within columns by Duncan's multiple range test, $P \leq 0.05$.

containing $5 \mu_{\mathrm{M}} 2,4-\mathrm{D}$ and $0.5 \mu \mathrm{M}$ Kin in the dark at $25^{\circ} \mathrm{C}$ for 6 weeks; 2) the cells should be passed through a 30-mesh stainless sieve to select cell clusters with diameter $\leq 520 \mu \mathrm{m} ; 3$ ) the screened cells should be inoculated onto MS-I medium containing 2.5 to $12.5 \mu \mathrm{M}$ Kin and 0.0 to $0.5 \mu \mathrm{M}$ NAA, then cultured in the dark at $25^{\circ} \mathrm{C}$ for 6 weeks; 4 ) the differentiated clumps should be transferred to MS-D medium containing $1.25 \mu \mathrm{m} \mathrm{BA}$ and incubated under light $\left(50 \mu \mathrm{mol} \cdot \mathrm{m}^{-2} \cdot \mathrm{s}^{-1}\right)$ at $23{ }^{\circ} \mathrm{C}$ for 6 weeks; 5) well-developed shoots and plantlets should be transferred to MS-R medium for root initiation and development; and 6) the rooted plantlets should then be transplanted to the greenhouse in a substrate containing 1 peatmoss : 1 pumice : 1 sandy loam (by volume).

Under these conditions, $\approx 8000$ plantlets $[\approx 400$ differentiated clumps/g cells $\times 15$ to 20 shoots/clump] can be regenerated from $1 \mathrm{~g}$ of iris suspension-cultured cells in $\approx 4$ months. The efficiency of this regeneration protocol is about twice that reported by Wang et al. (1999); about four times as high as that reported by Shimizu et al. (1997).

An efficient in vitro plant regeneration system is generally considered a prerequisite for genetic transformation, a novel approach for improving the characteristics of existing cultivars. Currently, we are using the system described above to develop a transformation protocol for Iris. This in turn will offer an attractive means for improvement of iris cultivars by introducing desirable traits into already proven cultivars. The system may also have application for large-scale propagation of newly developed cultivars. With an efficient plant regeneration system in place, the number of plants can be increased rapidly, thus shortening the time needed until new cultivars can be marketed.

\section{Literature Cited}

Fujimura, T. and A. Komamine. 1980. The serial observation of embryogenesis in a carrot cell suspension culture. New Phytol. 86:213-218.

Fujino, M., T. Fujimura, and K. Hamada. 1972. Multiplication of Dutch iris (Iris hollandica) by organ culture. J. Jpn. Soc. Hort. Sci. 41:66-71.

Gozu, Y., M. Yokoyama, M. Nakamura, R. Namba, K. Yomogida, M. Yanagi, and S. Nakamura. 1993. In vitro propagation of Iris pallida. Plant Cell Rpt. 13:12-16.

Halperin, W. 1966. Alternative morphogenetic events in cell suspensions. Amer. J. Bot. 53:443453

Hussey, G. 1976. Propagation of Dutch iris by tissue culture. Scientia Hort. 4:163-165.

Inoue, M. and E. Maeda. 1980. Effect of auxin and cytokinins on the occurrence of green regions in rice callus cultures. J. Jpn. Crop Sci. 49:167-174.

Jéhan, H., D. Courtois, C. Ehret, K. Lerch, and V. Petiard. 1994. Plant regeneration of Iris pallida Lam. and Iris germanica L. via somatic embryogenesis from leaves, apices and young flowers. Plant Cell Rpt. 13:671-675.

Kawase, K., H. Mizutani, M. Yoshioka, and S. Fukuda. 1995. Shoot formation on floral organs of Japanese iris in vitro. J. Jpn. Soc. Hort. Sci. 64:143-148.

Kohlein, F. 1987. Iris. Timber Press, Portland, Ore. Laublin, G., H.S. Saini, and M. Cappadocia. 1991. In vitro plant regeneration via somatic embryogenesis from root culture of some rhizomatous irises. Plant Cell Tiss. Org. Cult. 27:15-21.

Ling, D.H., W.Y. Chen, M.F. Chen, and Z.R. Ma. 1983. Somatic embryogenesis and plant regeneration in an interspecific hybrid of Oryza. Plant Cell Rpt. 2:169-171.

Meyer, M.M., Jr., L.H. Fuchigami, and A.N. Roberts. 1975. Propagation of tall bearded irises by tissue culture. HortScience 10:479-480.

Murashige, T. and F. Skoog. 1962. A revised medium for rapid growth and bioassays with tobacco tissue cultures. Physiol. Plant. 15:473497

Ozawa, K. and A. Komamine. 1989. Establishment of a system of high-frequency embryogenesis from long-term cell suspension cultures of rice (Oryza sativa L.). Theor. Appl. Genet. 77:205-211.

Radojević, L.J. and P. Landré. 1990. Ultrastructure studies of the somatic embryogenesis in Iris spp. cultures. Proc. 7th Intl. Congr. Plant Tissue and Cell Culture, Amsterdam, The Netherlands, (Abstr.) B4-100. 
Radojević, L.J., O. Sokić, and B. Tucić. 1987. Somatic embryogenesis in tissue culture of iris (Iris pumila). Acta Hort. 212:719-723.

Radojević, L.J. and A. Subotić. 1992. Plant regeneration of Iris setosa Pall. through somatic embryogenesis and organogenesis. J. Plant Physiol. 139:690-696.

Reuther, G. 1977. Embryoide Differenzierungsmuster im Kallus der Gattungen Iris und Asparagus. Ber. Deutsch. Bot. Ges. 90:417-437.

SAS Institute. 1987. SAS/STAT guide for personal computers. vers. 6. SAS Inst., Cary, N.C.

Shimizu, K., H. Nagaike, T. Yabuya, and T. Adachi. 1997. Plant regeneration from suspension culture of Iris germanica L. Plant Cell Tiss. Org. Cult. 50:27-31.

Shimizu, K., T. Yabuya, and T. Adachi. 1996. Plant regeneration from protoplasts of Iris germanica L. Euphytica 89:223-227.

Smith, S.M. and H.E. Street. 1974. The decline of embryogenetic potential as callus and suspension cultures of carrot (Daucus carota L.) are serially subcultured. Ann. Bot. 38:223-241.

Tsukahara, M. and T. Hirosawa. 1992. Characterization of factors affecting plantlet regeneration from rice (Oryza sativa L.) callus. Bot. Mag. Tokyo 105:227-233.

Tsukahara, M., T. Hirosawa, and S. Kishine. 1996. Efficient plant regeneration from cell suspension cultures of rice (Oryza sativa L.). J. Plant Physiol. 149:157-162.

van der Linde, P.C.G. and G.M.G.M. Hol. 1988. Tissue culture of Iris. Propagation is much improved. Bioembollen 99:36-37. van der Linde P.C.G., G.M.G.M. Hol, G.J. Blombarnboorn, J. van Aartrijk, and G.J. de Klerk. 1988. In vitro propagation of Iris hollandica Tub. cv. Prof. Blaauw. Regeneration on bulb scale explants. Acta Hort. 226:121-128.

Van Marrewijk, G.A.M. 1994. Prospects of biotechnology in horticultural breeding. Acta Hort. 369:199-219.

Waddick, J.W. and Y. Zhao. 1992. Iris of China. Timber Press, Portland, Ore.

Wang, Y., Z. Jeknic, R.C. Ernst, and T.H.H. Chen. 1999. Efficient plant regeneration from suspension-cultured cells of tall bearded iris. HortScience 34:730-735.

Yabuya, T., Y. Ikeda, and T. Adachi. 1991. In vitro propagation of Japanese garden iris, Iris ensata Thunb. Euphytica 57:77-81. 